\title{
Clinical Evaluation of Denture Retention by Multi-suction Cup and Denture Adhesive
}

\author{
Ahmed M. Shoeib ${ }^{1 *}$, Hesham S. Borg ${ }^{2}$ \\ ${ }^{1}$ Department of Removable Prosthodontics, Faculty of Dentistry, Al-Azhar University, Cairo, Egypt; ${ }^{2}$ Department of Removable \\ Prosthodontics, Faculty of Dentistry, 6th of October University, Cairo, Egypt
}

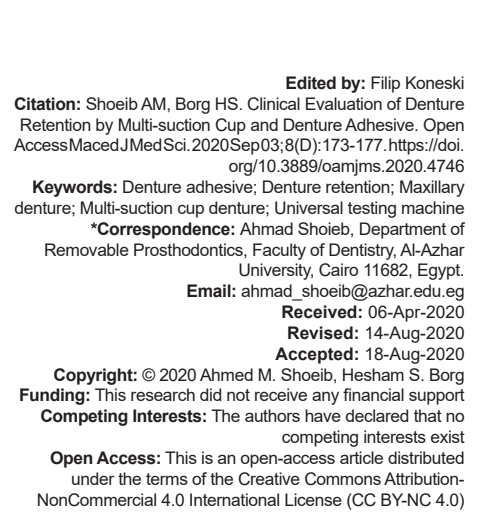

Abstract AIM: The aim of the study was to compare the retention of two modalities: Multi-suction cup denture, and denture
adhesive and to evaluate the change of retention by different time intervals.

PATIENTS AND METHODS: Twelve completely edentulous patients were selected. The patients received two dentures: One conventional denture, and the other with multi-suction cups. The retention was measured by a universal testing machine at insertion, $15 \mathrm{~min}, 30 \mathrm{~min}, 1 \mathrm{~h}, 2 \mathrm{~h}$, and $4 \mathrm{~h}$. All values were recorded in Newtons. Statistical analysis was carried out using two-way analysis of variance with post hoc Tukey's test.

RESULTS: Retention was higher in denture adhesive than multi-suction cup, and the change of retention was not statistically significant by time.

CONCLUSION: Denture adhesive showed better retention clinically and simplified laboratory procedures than multisuction denture.

\section{Introduction}

A variety of researches supports the use of conventional complete dentures to rehabilitate the edentulous maxilla. When contemplating the care of the edentulous maxilla, patients' standards for esthetic and phonetic (social) recovery are strong and can be met with the use of full maxillary dentures as the mode of the prosthesis [1]. Denture retention is the resistance in the movement of a denture away from its tissue foundation especially in a vertical direction [2]. The retention of their dentures is a fundamental concern of the edentulous patients. Total denture retention is a dynamic phenomenon, involving several variables. It has been found that objective and chewing ability were primarily influenced by denture retention or stability [3], [4].

Considerable experiments and research have been carried out and continue to be carried out on perfect dentures, which compensate for the loss of natural teeth. External forces and influences, such as air pressure, vacuum, adhesion, friction, wettability, surface roughness, gravity, surface tension, viscosity, base adaptation, boundary seal, and muscle strength, have been credited with causing or improving retention [5]. Various retentive aids have been developed to enhance the retention of dentures, including the use of soft liners, denture adhesives, multiple suction cups, and denture-based implants. It was thought that dental implants improve the retention of full dentures and assist with their support and stability; it is an important procedure for many edentulous patients. Nonetheless, in some cases, many patients cannot undergo implant surgery because of systemic factors, old age, and cost factors [6].

Adhesion usually implies a specific chemical interaction between the two solids interface. Whether this is by covalent bonds or chelation, the idea is a fixed molecular relationship and the fact that there is a separation resistance is called adhesion regardless of the inability to define a particular mechanism [7]. The use of suction cups in maxillary denture satisfies retention and stability requirements [4]. It has been found that the suction cup liner can be applied to both the upper and lower dentures. The suction cups device is highly useful for edentulous patients with irregular ridge morphology, flat ridges, bad healing, post-infection tissue healing, and long-term denture wear [8].

Denture adhesives are successful because they minimize the amount of lateral movements that occur when dentures are in contact with basal tissues. This advantage may lead a patient to neglect his or her need for professional help when he is ill, and these 
beneficial effects decrease over time as a result of an adhesive breakdown. The viscosity decreases slowly as the adhesive becomes thinner, and the retentive consistency loses over time [9].

In this study, we will compare the effect of adhesives and multi-suction cups on retention and patient satisfaction in complete maxillary denture wearer. The null hypothesis suggests that both denture adhesive and multi-suction cup had no effect on the complete denture retention by time.

\section{Aim of the study}

The aim of this study was to evaluate the effect of two modalities (multi-suction cup, and denture adhesive) on complete denture retention and also to evaluate the effect of time on denture retention of these modalities.

\section{Materials and Methods}

Twelve completely edentulous patients were selected from the outpatient clinic Prosthodontics Department, Faculty of Dental Medicine, Al Azhar University. Selection criteria were as the following: All patients were free from local or systemic disorder as confirmed by history taking and laboratory examinations, with history of loose denture complaint, no xerostomia, and with Class 4 residual ridge criteria according to American College of Prosthodontics classification (ridge height $<10 \mathrm{~mm}$ ) [10]. Patients had two dentures by duplicating the master cast: A complete denture constructed by the conventional protocol, and a denture with multiple suction cups. The protocol for the multi-suction cup was as the following [11]: Multiple trephine holes were cut inside the master cast after try-in (Figure 1). After flasking and before packing of acrylic resin in the mold, a wax spacer sheet was adapted over the cast and covered by a thin cellophane sheet, followed by packing of dough mix of hard heat cured acrylic resin ${ }^{1}$ over it, then the flask was closed and any excess acrylic was removed, the flask was opened again to replace the wax spacer by another dough mix of soft heat cured acrylic resin ${ }^{2}$, the curing cycle was $75^{\circ} \mathrm{C}$ for $1.5 \mathrm{~h}$, then by $100^{\circ} \mathrm{C}$ for an additional $1 \mathrm{~h}$, and the dentures were finished and polished (Figure 2). The dentures were grouped in to three groups according to the retention modality:

- $\quad$ Control Group: Conventional denture without Adhesive.

- Group II: Conventional denture with the addition of adhesive ${ }^{3}$.

- $\quad$ Group III: Denture with multi-suction cups.

1 Vertex Regular. Vertex-Dental B.V. Netherland

2 Vertex soft. Vertex-Dental B.V. Netherland

3 Fitty dent super adhesive. Fittydent International. Austria

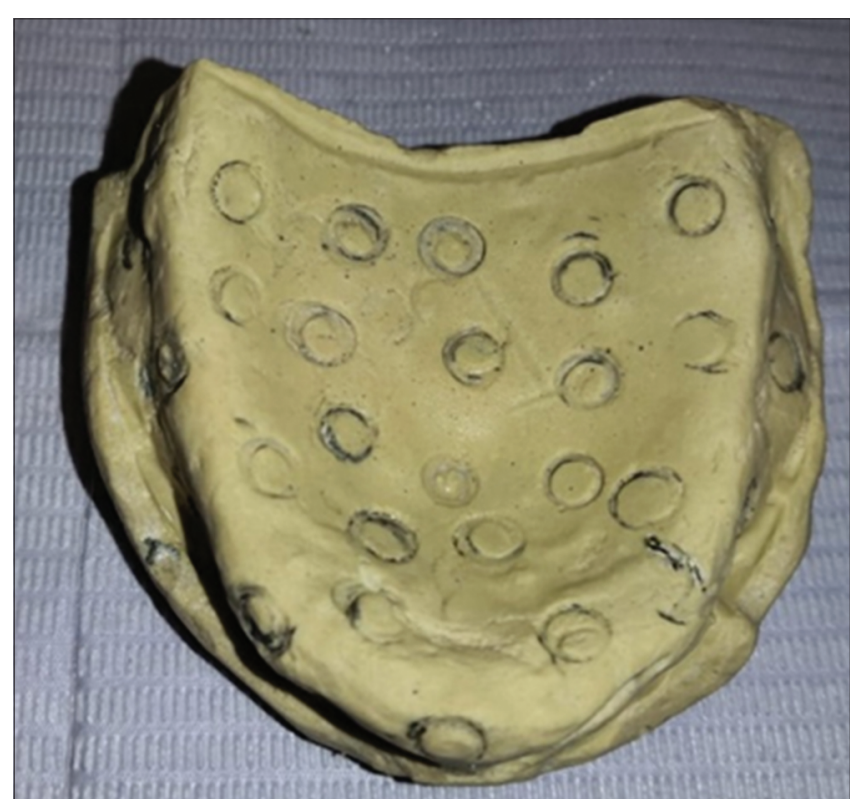

Figure 1: Denture with multi-suction cups

The device used for the measurement of denture retention was a universal test machine. To attach the metal rods of the machine to the denture, modification of the denture by drilling two holes at the canine area and fixing $3 \mathrm{~mm}$ metal tubes in them by self-cured acrylic resin. The patient sit with his head in upright position, then the pins of the metallic rods of the universal test machine were fixed to the metal tubes of the denture, and the machine applies a downward force until the denture was detached, the amount of dislodged force was recorded in Newtons at insertion, $15 \mathrm{~min}, 30 \mathrm{~min}, 1 \mathrm{~h}, 2 \mathrm{~h}$, and $4 \mathrm{~h}$ [12], [13].

The data of this study were shown as a mean and standard deviation (SD). The results showed a normal

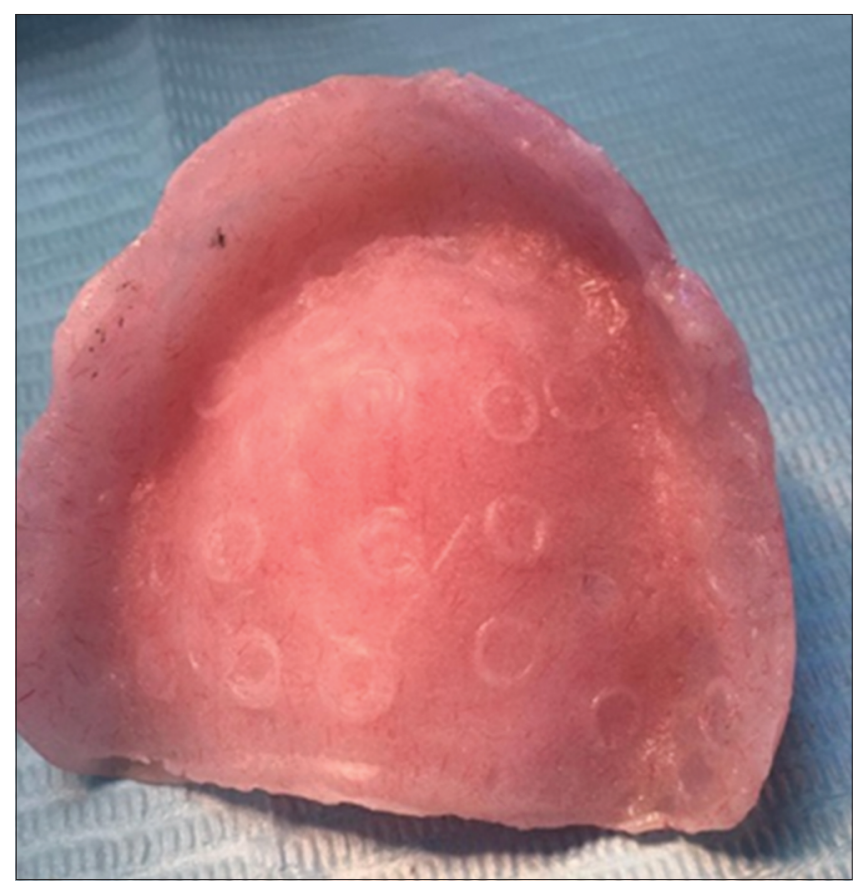

Figure 2: Trephination holes in cast 
distribution of data by Shapiro-Wilk test. The statistical analysis used the two-way repeated measures analysis of variance (ANOVA) test to compare the retention of three groups and post hoc Tukey's test for the effect of time on retention. The significance level was set at $p \leq 0.05$. The software used for statistical analysis was IBM SPSSC Statistics Version 20 for Windows.

\section{Results} SD of data.

Table 1 and Figure 3 show the mean and the

Table 1: Mean \pm SD of retention values of three groups at different time intervals in Newtons

\begin{tabular}{llll}
\hline Period & Control & Group I & Group II \\
\hline Before & $7.96 \pm 2.07$ & $8.75 \pm 1.92$ & $7.96 \pm 2.77$ \\
$15 \mathrm{~min}$ & $6.77 \pm 1.93$ & $31.31 \pm 8.48$ & $15.98 \pm 3.97$ \\
$30 \mathrm{~min}$ & $10.09 \pm 3.96$ & $32.11 \pm 7.00$ & $15.45 \pm 3.82$ \\
$1 \mathrm{~h}$ & $8.25 \pm 2.11$ & $32.34 \pm 7.80$ & $16.78 \pm 4.55$ \\
$2 \mathrm{~h}$ & $11.66 \pm 2.78$ & $34.17 \pm 12.97$ & $14.74 \pm 4.63$ \\
$4 \mathrm{~h}$ & $9.66 \pm 3.04$ & $29.47 \pm 10.70$ & $14.36 \pm 5.69$ \\
\hline
\end{tabular}

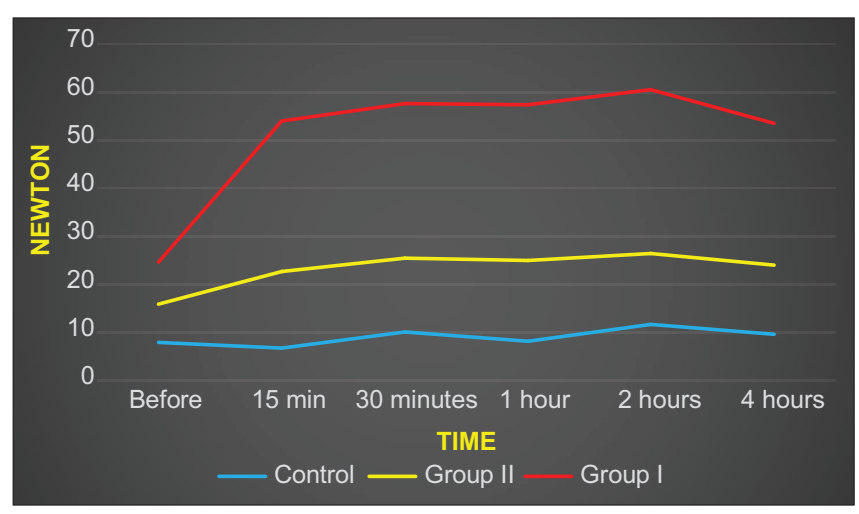

Figure 3: Retention values of three groups over time

Two-way ANOVA showed increase in retention by the effect of time or different group modalities (Table 2).

Table 2: Two-way ANOVA test of effects between subjects

\begin{tabular}{llll}
\hline Dependent variable: & Retention & & \\
\hline Source & Mean square & F & Sig. \\
\hline Time & 472.043 & 11.900 & 0.000 \\
Groups & 4621.093 & 116.491 & 0.000 \\
\hline
\end{tabular}

Data showed increase in the retention values in both groups, which were statistically significant different from the control group. Group I was higher in retention than Group II, which statistically significant by post hoc Tukey's test (Table 3).

Table 3: Post hoc Tukey's test for multiple comparison between groups

\begin{tabular}{lllll}
\hline (I) type & $(\mathrm{J})$ type & Mean difference $(\mathrm{I}-\mathrm{J})$ & p value & Significance \\
\hline Control & Group I & -18.9718 & 0.000 & Significant \\
& Group II & $-5.1417^{*}$ & 0.000 & Significant \\
Group I & Group II & $-13.8301^{*}$ & 0.000 & Significant \\
\hline
\end{tabular}

Data show that increase retention with time in Groups I, II. However, the control group did not show any increase. Retention reaches its peak after $1 \mathrm{~h}$ in Group I, and $2 \mathrm{~h}$ in Group II. Post hoc turkey test showed statistically significant different between insertion and after all times. In between time comparison, no statistically non-significant difference observed (Table 4).

Table 4: Post hoc Tukey's test for different times comparison

\begin{tabular}{|c|c|c|c|c|}
\hline (I) time & (J) time & Mean difference (I-J) & Sig & Significance \\
\hline \multirow[t]{5}{*}{ Insertion } & $15 \min$ & $-9.8029^{*}$ & 0.000 & Significant \\
\hline & $30 \mathrm{~min}$ & $-11.0012^{*}$ & 0.000 & Significant \\
\hline & $1 \mathrm{~h}$ & $-10.9012^{*}$ & 0.000 & Significant \\
\hline & $2 \mathrm{~h}$ & $-11.9662^{\star}$ & 0.000 & Significant \\
\hline & $4 \mathrm{~h}$ & $-9.6052^{\star}$ & 0.000 & Significant \\
\hline \multirow[t]{4}{*}{$15 \mathrm{~min}$} & $30 \mathrm{~min}$ & -1.1983 & 0.986 & Non-significant \\
\hline & $1 \mathrm{~h}$ & -1.0983 & 0.991 & Non-significant \\
\hline & $2 \mathrm{~h}$ & -2.1633 & 0.841 & Non-significant \\
\hline & $4 \mathrm{~h}$ & 0.1977 & 1.000 & Non-significant \\
\hline \multirow[t]{3}{*}{$30 \mathrm{~min}$} & $1 \mathrm{~h}$ & 0.1000 & 1.000 & Non-significant \\
\hline & $2 \mathrm{~h}$ & -0.9650 & 0.995 & Non-significant \\
\hline & $4 \mathrm{~h}$ & 1.3960 & 0.972 & Non-significant \\
\hline \multirow[t]{2}{*}{$1 \mathrm{~h}$} & $2 \mathrm{~h}$ & -1.0650 & 0.992 & Non-significant \\
\hline & $4 \mathrm{~h}$ & 1.2960 & 0.980 & Non-significant \\
\hline $2 \mathrm{~h}$ & $4 \mathrm{~h}$ & 2.3610 & 0.785 & Non-significant \\
\hline
\end{tabular}

\section{Discussion}

Unacceptable complete retention and stability of the complete denture are a significant risk factor in total edentulism. Patient satisfaction was directly correlated with perceived general health, and indirectly with the oral health. Maintaining optimum retention of dentures and consistency in denture wearers is therefore necessary for good oral health and well-goal of enhancing happiness [14].

The patients in this study were selected free of systemic diseases that may impair denture retention as Parkinson's disease, hemiplegia, or any defects in the temporomandibular joint as they may result in prosthetic failure due to lack of neuromuscular control [15], as diabetics have increased predisposition to oral diseases such as candidiasis associated with xerostomia [16]. Patients with xerostomia were all omitted as the saliva is essential to the retention of removable prostheses as salivary wetting mechanics are required to establish adhesion, stability, and surface tension that eventually contribute to increased prosthesis retention [17]. Retention was measured by a universal testing system that is a standardized precision measurement tool for retention [18].

Our finding was accepted with Chandrakala [19] explaining the definition of a simple technique for enhancing denture retention and stability using the multisuction cup denture liner. It provided a viable option to improve denture retention when the patient was unable to use other treatment methods. These suction cups grip the oral tissue, providing an increased surface area for improved retention and an improved suction force for resistance [8]. When properly positioned, the multi-suction cup denture liner has provided a viable alternative to 
enhancing denture retention when pre-prosthetic surgery may not have been feasible or desired by the patient [20]. Jermyn [21] showed that there are focal areas of mild inflammation where a hole had been too deeply drilled. However, holes of sufficient depth did not displace tissues to the point of inflammation or pathology caused by the suction cups. There have been numerous case reports of mucosal ulceration or palatal perforation caused by the use of single suction cup in maxillary dentures [22], [23]. Indeed, it has to be noted that the multi-suction cup denture require an additional laboratory steps for its fabrication.

In this study, the adhesives give the most retention results than multi-suction cup and conventional complete denture lies in agreement with Lindstrom et al. [24], who addressed the role of denture adhesives in denture retention and stability by counting denture dislodgments in patients eating standardized portions of food (celery, apple, steak, and hard roll sandwich), with and without adhesives. Modern adhesives have a carboxyl groups which provide solid bioadhesive and cohesive forces. Polymethyl vinyl ether-maleic anhydride copolymer is a synthetic compound that is commonly used in denture adhesives due to its high carboxyl group levels. The most widely used agent is sodium carboxymethyl cellulose, or $\mathrm{CMC}$, a naturally derived adhesive ingredient, due to its carboxylic groups [25]. While it provides a good initial hold when used alone, due to its high solubility, CMC dissolves easily. Manufacturers introduced products which combined zinc PVM-MA with CMC calcium salts. Due to the stronger covalent bond which develops through the divalent zinc action, these materials provided even greater cohesive strength for longer durations [26].

Patient satisfaction with denture adhesive was dependent on several factors such as: Adhesive length in the mouth of the patient, taste and elimination of adhesive from the mouth of the patient. Improvement of chewing capacity was observed using different types of adhesive but there was negligible difference between them [27]. Indeed, Abolmasov et al. found that separation force increases when the thickness of the denture adhesive cream decreases [28].

\section{Conclusion}

Denture adhesives had the best retention values followed by multi-suction cup denture, and the amount of retention showed no significant changes in all observation times of both groups.

\section{References}

1. Thalji G, McGraw K, Cooper L. Maxillary complete denture outcomes: A systematic review of patient-based outcomes.
Int J Oral Maxillofac Implant. 2017;31:s169-81. https://doi. org/10.11607/jomi.16suppl.g5.1

PMid:27228248

2. Ferro KJ. The glossary of prosthodontic terms. J Prosthet Dent. 2017;117:31.

3. Limpuangthip N, Somkotra T, Arksornnukit M. Subjective and objective measures for evaluating masticatory ability and associating factors of complete denture wearers: A clinical study. J Prosthet Dent. 2020;In press. https://doi.org/10.1016/j. prosdent.2020.01.001

4. Rao Y, D'Souza M, Porwal A, Yadav P, Kumar S, Aggarwal A. Clinical and histopathological changes in palatal mucosa following two treatment modalities in patients wearing maxillary complete dentures with suction cup. Contemp Clin Dent. 2014;5(2):150-4. https://doi.org/10.4103/0976-237x.132301 PMid:24963236

5. Darvell B, Clark R. The physical mechanisms of complete denture retention. Br Dent J. 2000;189(5):248-52. https://doi. org/10.1038/sj.bdj.4800734a

PMid:11048392

6. Sayed F, Sanad M, Omar O, Youssef $H$. The effect of using ultra suction system on mandibular complete denture retention. Azhar Dent J Girls. 2016;3(3):161-9. https://doi.org/10.21608/ adjg.2016.5083

7. Murray M, Darvell B. The evolution of the complete denture base. Theories of complete denture retention-a review. Part 4. Aust Dent J. 1993;38(6):450-5. https://doi. org/10.1111/j.1834-7819.1993.tb04760.x

PMid:8110080

8. Shuman I. The suction cup denture. A century-old technology reborn. Dent Today. 2004;23(1):72-7.

PMid:14969001

9. Kumar P, Shajahan P, Mathew J. The effect of denture adhesive on mandibular movement during chewing. J Am Dent Assoc. 2000;131(7):981-6.

PMid: 10916336

10. McGarry T, Nimmo A, Skiba J, Ahlstrom R, Smith C, Koumjian J Classification system for complete edentulism. The American college of prosthodontics. J Prosthodont. 1999;8(1):27-39. https://doi.org/10.1111/j.1532-849x.1999.tb00005.x PMid:10356552

11. Vasant R, Bassi G. Use of the multi-cup denture for a severely resorbed maxilla: A clinical report. $\mathrm{Br}$ Dent $\mathrm{J}$. 2012;212(9):431-4. https://doi.org/10.1038/sj.bdj.2012.369 PMid:22576499

12. Ibraheem E, El-Sisy A. Comparing the effect of three denture adhesives on the retention of mandibular complete dentures for diabetic patients (randomized clinical trial). Bull Natl Res Cent. 2019;43:24. https://doi.org/10.1186/s42269-019-0052-7

13. Salem S, Abd El-Fattah A, Shereen M, Ibraheem E, El-Zawahry M. A comparative study between telescopic and ball and socket attachments used for maxillary implant supported single dentures. Azhar Dent J Girls. 2020;7(1):67-72. https://doi. org/10.21608/adjg.2019.7707.1093

14. Limpuangthip N, Somkotra T, Arksornnukit M. Impacts of denture retention and stability on oral health-related quality of life, general health, and happiness in elderly thais. Curr Gerontol Geriatr Res. 2019;2019:1-8. https://doi.org/10.1155/2019/3830267

15. Winkler S. Essentials of Complete Denture Prosthodontics. $3^{\text {rd }}$ ed. New Delhi: AITBS; 2013.

16. Barbeau J, Séguin J, Goulet J, De-Koninck L, Avon S, Lalonde B, et al. Reassessing the presence of Candida albicans in denturerelated stomatitis. Oral Surg Oral Med Oral Pathol Oral Radiol Endod. 2003;95(1):51-9. https://doi.org/10.1067/moe.2003.44 PMid:12539027 
17. Turner M, Jahangiri L, Ship J. Hyposalivation, xerostomia and the complete denture. J Am Dent Assoc. 2008;139(2):146-50. https://doi.org/10.14219/jada.archive.2008.0129

PMid:18245681

18. Feine J, Maskawi K, De-Grandmont P, Donohue W, Tanguay R, Lund J. Within-subject comparisons of implant-supported mandibular prostheses: Evaluation of masticatory function. $\mathrm{J}$ Dent Res. 1994;73(10):1646-56. https://doi.org/10.1177/00220 345940730101001

PMid:7929979

19. Chandrakala V. Restoration of the severely resorbed maxilla and mandible using the multicup denture. World $\mathrm{J}$ Dent. 2011;2:346-9. https://doi.org/10.5005/jp-journals-10015-1111

20. Engelmeier R, Gonzalez M, Harb M. Restoration of the severely compromised maxilla using the multi-cup denture. J Prosthodont. 2008;17(1):41-6. https://doi. org/10.1111/j.1532-849x.2007.00241.x PMid:17927734

21. Jermyn A. Multiple suction cup dentures. J Prosthet Dent. 1967;18(4):316-25.

PMid:4860359

22. Cayetano O, Boone M. Suction cups on maxillary dentures: Report of case. J Am Dent Assoc. 1987;115(4):577. https://doi. org/10.1016/s0002-8177(87)54011-9

PMid:3308999
23. Ordulu M, Emes $\mathrm{Y}$, Ates M, Aktas I, Yalçin S. Oronasal communication caused by a denture with suction cup: A case report. Quintessence Int. 2006;37(8):659-62.

PMid: 16922027

24. Lindstrom R, Pawelchak J, Heyd A, Tarbet W. Physicalchemical aspects of denture retention and stability: A review of the literature. J Prosthet Dent. 1979;42(4):371-5. https://doi. org/10.1016/0022-3913(79)90134-3

PMid:385837

25. Kumar R, Shajahan $P$, Mathew J, Koruthu A, Aravind $P$, Ahammed F. Denture adhesives in prosthodontics: An overview. Int J Oral Health. 2015;7(1):93-5.

PMid:26225115

26. SmitaM,RamandeepD, MukundK.Areviewofdentureadhesives used in the dental profession. Ann Ess Dent. 2010;2:129-33. https://doi.org/10.5368/aedj.2010.2.3.129-133.pdf

27. El-Mekawy N, Gomaa A, Habib A. Comparison of three different forms of denture adhesives: Direct measurement of denture retention and, study of patient satisfaction. Egypt Dent $\mathrm{J}$. 2012;58(3):1-9.

28. Abolmasov N, Adaeva A, Verkhovskiy N, Anisov V. Adhesive remedies for dentures. Myths and reality (laboratory research). Stomatologiia (Mosk). 2019;98(6):90-5. https://doi.org/10.17116/ stomat20199806190

PMid:31922517 